\title{
PROGRAMA DE AUXÍLIO MORADIA EM UMA UNIDADE ACADÊMICA DE UMA UNIVERSIDADE DE PERNAMBUCO: UMA AVALIAÇÃO NA PERSPECTIVA DOS (AS) DISCENTES BENEFICIADOS
}

\author{
PROGRAMA DE AYUDA A LA VIVIENDA EN UNA UNIDAD ACADÉMICA DE \\ UNA UNIVERSIDAD DE PERNAMBUCO: UNA EVALUACIÓN DESDE LA \\ PERSPECTIVA DE LOS BENEFICIARIOS
}

\author{
HOUSING ASSISTANCE PROGRAM IN AN ACADEMIC UNIT OF A \\ UNIVERSITY OF PERNAMBUCO OF PERNAMBUCO: AN EVALUATION FROM \\ THE PERSPECTIVE OF BENEFIT STUDENTS
}

Lilian da Silva BRITO ${ }^{1}$

Alba BARBOSA ${ }^{2}$

RESUMO: O artigo procurou analisar um Programa de Auxílio Moradia desenvolvido em uma Unidade Acadêmica de uma Universidade em Pernambuco, através da percepção dos discentes beneficiados. O Programa Nacional de Assistência Estudantil, Decreto $\mathrm{n}^{\mathbf{o}}$ 7.234/10, dispõe que as instituições federais de ensino devem fixar mecanismos de avaliação. O estudo é qualitativo e descritivo e utilizou como coleta de dados um questionário aplicado com todos os beneficiários do referido programa. Concluiu-se que o programa, contribui para minimizar as desigualdades socioeconômicas, tendo em vista as iniciativas voltadas para a democratização do acesso e a formação para a cidadania, bem como a permanência no curso.

PALAVRAS-CHAVE: Assistência estudantil. Ensino superior. Políticas públicas.

RESUMEN: El artículo buscó analizar un programa de ayuda a la vivienda desarrollado en una unidad académica de una Universidad en Pernambuco, a través de la percepción de los beneficiarios. El programa nacional de asistencia estudiantil, Decreto No. 7.234/10, establece que las instituciones educativas federales deben fijar los mecanismos de evaluación. El estudio es cualitativo y descriptivo y se utiliza como recopilación de datos un cuestionario aplicado con todos los beneficiarios del dicho programa. Se concluye que el programa contribuye a minimizar las desigualdades socioeconómicas, con miras a las iniciativas encaminadas a democratizar el acceso y la formación para la ciudadanía, así como la permanencia en el curso.

\footnotetext{
${ }^{1}$ Mestranda no Programa de Pós-graduação em Gestão Pública para o Desenvolvimento do Nordeste pela Universidade Federal de Pernambuco. Especialista em Gestão Pública pelo Instituto Federal de Pernambuco (2016). Graduada em Serviço Social pela Universidade Federal de Pernambuco (2012). Email: lilians.brito@hotmail.com

${ }^{2}$ Doutora em Administração pela Universidade Federal do Rio Grande do Norte (2013). Professora do Instituto Federal de Pernambuco nos cursos de nível técnico, tecnológico e especialização desde 2005. Email: alba.barbosa@paulista.ifpe.edu.br
} 
PALABRAS CLAVE: Asistencia estudiantil. Educación superior. Política pública.

ABSTRACT: This article aims to contribute to decision-making, and provide the executors of Student Assistance Programs in the Academic Unit of Cabo de Santo Agostinho da Universidade Federal Rural de Pernambuco, in perfecting the developed actions. The National Programme of Student Assistance, Decree $n^{\circ} .7,234$ / 10 provides that federal education institutions should establish mechanisms for evaluation, thus to carry out the analysis, was used as a data collection tool, a questionnaire with closed questions and open. The questionnaire was developed from 05 directions: the first the student's profile; on the degree of relevance of aid; the degree of satisfaction; how the aid was intended and suggestions for improving the program implementation. It was concluded that the program helps to reduce socioeconomic inequalities, in view of the initiatives aimed at democratizing access and training for citizenship and staying the course.

KEYWORDS: Student care. Higher education. Public policy.

\section{Introdução}

A ampliação das Universidades Federais através do Programa de Apoio a Planos de Reestruturação e Expansão das Universidades Federais (REUNI) implantado pelo Decreto n 6.096 de 24 de abril de 2007 no governo do Presidente Luiz Inácio Lula da Silva, transformou significativamente o ensino superior público, uma vez que o processo de expansão oportunizou a interiorização das Universidades Federais, bem como a criação de novas vagas nessas Instituições.

Nesse sentido, ressalta-se ainda como mecanismos para a democratização da educação, as políticas de acesso ao ensino superior, tais como: a política de cotas, reafirmada pela Lei $\mathrm{n}^{\circ}$ 12.711/12 que prevê a reserva mínima de 50\% das vagas até 2016, para os (as) discentes provenientes das escolas públicas de ensino médio, bem como os programas de expansão como o Exame Nacional do Ensino Médio (Enem) e o Sistema de Seleção Unificada (Sisu), que permitem o ingresso de estudantes em situação de vulnerabilidade socioeconômica na universidade pública.

Destarte, verifica-se que as transformações das universidades públicas nas últimas décadas resultaram em uma crescente universalização da educação superior brasileira, conforme demonstram os dados do Sistema Eletrônico do Serviço de Informação ao Cidadão do Ministério da Educação (SIC/MEC, 2016).

Esses mesmos dados destacam que o processo de interiorização ocorrido a partir dos anos de 2003, proporcionou uma ampliação na disponibilidade de vagas nas Instituições 
Federais de Ensino Superior (IFES) que elevou o número de universidades federais, passando de 114 municípios atendidos para 289, representando um aumento significativo de $153 \%$. Já entre o período de 2003 a 2014, houve um crescimento de 45 IFES para 63, o que significou um aumento de 40\%, e ainda de 148 campus para 321, uma expansão de $117 \%$ (SIC/MEC, 2016).

Destaca-se dentre as diversas metas previstas pelo REUNI, o art. 1 e parágrafo $1^{\circ}$ que dispõe sobre a elevação gradual da taxa de conclusão média dos cursos de graduação presenciais para 90\%; e da relação de alunos de graduação em cursos presenciais por professor para $18 \%$ ao final de cinco anos a contar do início de cada plano. Nesse contexto, compreende-se que o processo de expansão do ensino superior público tem possibilitado a entrada de estudantes de diversas camadas sociais nas universidades, desse modo influenciando no perfil socioeconômico dos (as) estudantes e consequentemente demandado por ampliação da Política de Assistência Estudantil (REUNI, 2007).

Alves (2002) pontua que a necessidade da democratização do ensino superior, está voltada não apenas as ações de acesso à universidade pública gratuita, como também os mecanismos para a permanência, reduzindo assim os efeitos das desigualdades. Verificase, portanto, a importância no desenvolvimento de uma política efetiva de assistência estudantil para atender às demandas voltadas para a saúde, alimentação, transporte, moradia, esporte, cultura, lazer, entre outras condições, visando então a permanência dos (as) discentes no ensino superior.

Vasconcelos (2010) define que a assistência estudantil transita em todas as áreas dos direitos humanos, compreendendo ações que proporcionem desde as ideais de condições de saúde, o acesso aos instrumentais pedagógicos necessários à formação profissional nas mais diferentes áreas do conhecimento, o acompanhamento às necessidades educativas especiais, até o provimento dos recursos mínimos para a sobrevivência do (a) estudante.

Nessa perspectiva o Programa Nacional de Assistência Estudantil (PNAES), instituído pelo Decreto $\mathrm{n}^{\mathrm{o}}$ 7234, de 10 de julho de 2010, tem como objetivos a democratização das condições de permanência, a redução das taxas de retenção e evasão, a contribuição para a promoção da inclusão social e minimização dos efeitos das desigualdades sociais e regionais na permanência e conclusão da educação superior (PNAES, 2010).

Através do processo de expansão, relatado anteriormente, a Universidade analisada neste artigo vem se consolidando no processo de interiorização, através da implantação de 
novas Unidades Acadêmicas no Estado de Pernambuco. A referida Unidade Acadêmica foi criada no ano de 2014, tendo realizado um dos seus primeiros processos seletivos voltados para a Assistência Estudantil no ano de 2015, denominado Programa de Auxílio Moradia.

O Programa de Auxílio Moradia, tem como principal objetivo assegurar auxílio financeiro aos discentes oriundos (as) de outros municípios que necessitam de moradia para cursar a universidade. O Processo de seleção, portanto, consiste no preenchimento de formulário socioeconômico, na apresentação de documentos, tais como documentos pessoais e comprovação de renda familiar; entrevista social e visita domiciliar no endereço da família. Em todas as etapas é analisado se o (a) candidato (a) atende os requisitos dispostos na Resolução e Edital do Programa que estão em conformidade com Política Nacional de Assistência Estudantil.

Nesse sentido a pesquisa de estudo, tem como finalidade fazer uma análise do Programa de Auxílio Moradia a partir da percepção dos (as) discentes beneficiados (as) na Unidade Acadêmica de uma Universidade em Pernambuco.

A pesquisa, portanto, consiste especialmente em contribuir para à tomada de decisões das ações da assistência estudantil de forma mais eficaz, pois compreende-se que a avaliação propicia que os atores executores da política identifiquem as necessidades de aperfeiçoar as práticas já existentes, assim fortalecendo os seus objetivos.

\section{Referencial teórico}

O referencial teórico busca analisar a política de assistência estudantil na educação superior, portanto, a princípio fez se necessário conhecer o processo histórico da Assistência Estudantil no contexto nacional, através do processo de expansão do ensino superior. Em segundo momento, com o intento de compreender em que medida as políticas públicas contribuem para a igualdade e autonomia do sujeito, fez se importante entender como se dá a sua avaliação.

\section{Expansão do ensino superior}

Com o processo de Redemocratização do Brasil e promulgação da Constituição Federal de 1988, a educação passou a ser considerada como um direito de todos e dever do Estado e da família ao pleno desenvolvimento da pessoa. A CF/88 no seu art. 205, explicita que a educação é "direito de todos e dever do Estado e da família, será promovida e 
incentivada com a colaboração da sociedade, visando ao pleno desenvolvimento da pessoa, seu preparo para o exercício da cidadania e sua qualificação para o trabalho" (BRASIL, 1988). A educação trata-se, portanto, de um direito fundamental e universal que visa o pleno desenvolvimento dos sujeitos sociais para o seu exercício de cidadania.

Oliveira (1998) pontua que a $\mathrm{CF} / 88$ foi a primeira que contemplou de modo explícito os direitos sociais, enfatizando a educação como um direito universal. Aranha (2006), por sua vez também afirma que a CF/88 marcou a história da educação brasileira e garantiu importantes conquistas advindas de lutas dos movimentos sociais, dos professores e dos estudantes, podendo destacar-se: a gratuidade do ensino público, a autonomia universitária, a aplicação de mais recursos pelos entes federativos à educação, etc.

Nesse contexto compreende-se que com a promulgação da CF/88, a educação passa a ser atribuída como um direito público em que todas as pessoas, independente de classe social e idade, possam usufruir de um serviço de qualidade, devendo o Estado proporcionar condições para que todos tenham acesso de modo igualitário a esse direito.

Nesse sentido, segundo Georgen (2010), nos últimos anos a educação superior tem ganhado maior destaque na sociedade brasileira, uma vez que está diretamente relacionada à produção de conhecimentos e que consequentemente tem contribuído com o processo de industrialização. Assim, importa-se destacar o processo de expansão das Instituições Federais de Ensino Superior (IFES), ocorrido com a implantação do Programa de Apoio a Planos de Reestruturação e Expansão das Universidades Federais (REUNI), tem oportunizado a interiorização e ampliação de vagas das IFES.

Destarte, compreende-se que a ampliação do ensino superior, através das políticas de expansão e afirmativas tem oportunizado a entrada de estudantes de camadas populares no ensino superior público.

Nesse sentido, Baggi (2010) afirma que ao mesmo tempo em que houve um significativo aumento na entrada de estudantes no ensino superior, houve também um elevado número de discentes evadidos (as). Define, portanto que a evasão pode estar atrelada ao contexto social, cultural, político e econômico e especialmente pode se relacionar com a qualidade de ensino oferecida; dificuldades do (a) aluno (a) no currículo apresentado pela instituição; dificuldades na didática dos professores; necessidade do ingresso do (a) aluno (a) no mercado de trabalho; etc.

Já Dantas e Araújo (2005) referem que os (as) discentes em situação de fragilidade socioeconômica tem mais dificuldades em dar continuidade aos estudos, quando a 
instituição de ensino não disponibiliza programas de assistência estudantil, tais como: restaurante universitário, moradia, transporte etc. Destarte, compreende-se que as ações de assistência estudantil preconizadas pelo Programa Nacional de Assistências Estudantil (PNAES), traz em sua essência a viabilização da igualdade de direitos, contribuindo assim para a melhoria do desempenho acadêmico do discente e consequentemente minimizando as situações de evasão decorrentes da insuficiência de condições financeiras.

Portanto, vale salientar a importância da efetivação de estratégias e mecanismos democráticos na perspectiva de inclusão social, qualidade de vida e igualdade de permanência dos (as) discentes na universidade, como também a importância de identificar os desafios e potencialidade da política de assistência estudantil, visto que esta política traz elementos essenciais de discussão, no sentido de contribuir para um projeto de sociedade cada vez mais justo e igualitário, assim reduzindo as contradições existentes dentro das universidades e equalizando assim as oportunidades de ascensão social através da educação.

Portanto, compreende-se que as políticas públicas de educação devem ter suas ações em consonância com a concretização dos direitos sociais, considerando, assim, ser fundamental que o poder público, por meio de políticas sociais, viabilize a assistência ao educando socioeconomicamente vulnerável de usufruir plenamente das diversas possibilidades que o espaço acadêmico possa proporcionar.

\section{Metodologia}

A pesquisa realizada trata-se de uma abordagem qualitativa e descritiva, cujo objetivo principal foi descrever a percepção dos estudantes beneficiários por Programas de Assistência estudantil de uma Universidade Federal em localizada em Pernambuco. Ressalta-se que com base no conceito destacado por Marconi e Lakatos (2009), compreende-se que a metodologia qualitativa se preocupa especialmente em analisar e interpretar os aspectos mais profundos de uma pesquisa, pois descreve a complexidade do comportamento humano e fornece, portanto, análise mais detalhada sobre as investigações, hábitos, atitudes e tendências de comportamento.

Nesse sentido, ainda cabe ressaltar que a investigação também foi realizada a partir de documentos oficiais disponíveis pela instituição de ensino (Resoluções dos Programas, Editais e Relatório de Gestão), como fonte secundária de informação. Destaca-se que 
foram realizados estudos bibliográficos que possibilitou uma maior abrangência das considerações relacionadas ao tema, consultas de legislações que tratam do Programa Nacional de Assistência Estudantil (PNAES) e que subsidiou no aprofundamento do tema.

Os sujeitos envolvidos na pesquisa foram os discentes beneficiários do Programa de Auxílio Moradia da Unidade Acadêmica, que perfaz um total de 18 alunos. Utilizou-se como instrumento de coletas de dados, um questionário organizado através de perguntas fechadas e abertas, que teve como finalidade a partir da percepção dos (as) beneficiários (as) compreender o grau de satisfação e relevância do auxílio de moradia na vida dos (as) acadêmicos (as).

Ressalta-se que no processo de aplicação do questionário, identificou-se o perfil dos (as) discentes assistidos (a) pelo Programa, 11 estudantes do sexo masculino e 07 do sexo feminino, com a idade entre 19 anos a 24 anos. Destarte, esclareceu-se que a identificação individual era desnecessária, de modo que garantisse o anonimato dos (as) respondentes

No que diz respeito à aplicação do questionário, foi realizada durante o período de 03 dias (sexta, segunda e terça) do mês de junho de 2016. O (a) discente foi contactado (a) por telefone e por e-mail, informações disponíveis no banco de dados, para participarem da pesquisa. Salienta-se ainda que para a realização do estudo, foi solicitada autorização através de documento formal à Direção Geral e Acadêmica da Unidade de Ensino.

O questionário foi desenvolvido a partir de 05 direcionamentos: a princípio o perfil do (a) discente beneficiado(a); depois sobre o grau de relevância do auxílio moradia; posteriormente sobre o seu grau de satisfação; de como o auxílio recebido era destinado e por fim as sugestões do(a) estudante para melhorar a execução do Programa.

Por fim, os dados coletados foram submetidos ao Microsoft Excel, gerando gráficos, de maneira a ter conclusões em termos quantitativos e interpretações qualitativos.

\section{Descrição e análise de dados}

Em consonância com o projeto de expansão do Ensino Superior, a Universidade Federal em questão tem estendido suas ações através da implantação das Unidades Acadêmicas. Verifica-se que os cursos de graduação das Unidades, tem como principal finalidade atender a demanda local, influenciando, portanto, no desenvolvimento regional. Nesse contexto de transformações do ensino superior público através das políticas de expansão e de ações afirmativas, entende-se, que o perfil dos (as) discentes inseridos (as) 
nas IFES, são provenientes de diversas camadas sociais, apresentando indicadores de vulnerabilidade socioeconômica que podem dificultar a vida acadêmica.

Antes de apresentar a análise do Programa de Moradia Estudantil realizado pelos docentes beneficiados, optou-se por retratar brevemente o Programa de Assistência Estudantil da Universidade, o qual está atrelado ao Programa Nacional de Assistência Estudantil (PNAES). O PNAES, foi um importante instrumento de regulação da assistência estudantil no Brasil, pois tomou a posição de política pública.

Em 1996 foi aprovada a Lei de Diretrizes e Bases da Educação Nacional (LDBEN), Lei ${ }^{\circ}$ 9394/96, que trouxe diversas alterações na sistemática do ensino superior no Brasil, pois segundo alguns autores ela delimita o início da reestruturação do ensino superior. Desse modo, verifica-se que a partir da aprovação da LDBEN/96, as ações de assistência estudantil foram reiteradas como imprescindíveis para a garantia de acesso e permanência dos (as) discentes em situação de fragilidade socioeconômica.

Nesse contexto, no ano de 2007, foi aprovado pelo Ministério da Educação (MEC) a Portaria Normativa $n^{\circ}$ 39, de 12 de dezembro de 2007, que instituiu o Programa Nacional de Assistência Estudantil - PNAES, sendo o Programa reafirmado posteriormente por meio do Decreto $\mathrm{n}^{\mathrm{o}} 7234$, de 10 de julho de 2010.

Nesse sentido, a política de assistência estudantil, uma vez caracterizada como política social de educação, tem como principal finalidade contribuir para minimizar os efeitos das desigualdades sociais através de mecanismos que viabilizem a permanência de estudantes em situação de vulnerabilidade socioeconômica nos cursos de graduação, bem como contribuir para a promoção da inclusão social pela educação.

Ressalta-se que na Universidade Federal, objeto de análise desse artigo, os programas de assistência estudantil estão baseados na Programa Nacional de Assistência Estudantil (PNAES). A implementação e gerenciamento dos Programas de assistência estudantil estão sob a responsabilidade da Pró-Reitoria de Gestão Estudantil e Inclusão (PROGESTI) e a sua execução em cada uma das Unidades Acadêmicas conta com o apoio das Coordenadorias de Gestão Estudantil (COGEST), constituídas por uma equipe de profissionais, tais como: assistentes sociais, psicólogos (as), técnicos em assuntos educacionais, assistentes administrativos e pedagogos (as).

A Pró-Reitoria de Gestão Estudantil e Inclusão (PROGESTI) oferece várias modalidades de apoio aos discentes, dentre as quais estão, os Programa de concessão de bolsas e auxílios, como também oferece outros programas de ajuda de custo, serviços de 
apoio psicossocial e pedagógico, conforme o Quadro 1, a seguir:

Quadro 1: Programas de concessão de bolsas e auxílios da Universidade

\begin{tabular}{|c|c|}
\hline PROGRAMA & FINALIDADE \\
\hline $\begin{array}{l}\text { Apoio ao } \\
\text { Ingressante } \\
\text { (PAI) }\end{array}$ & $\begin{array}{l}\text { Tem por finalidade apoiar os (as) discentes ingressantes que vivenciam situação de } \\
\text { vulnerabilidade socioeconômica, através de auxílios transporte ou alimentação. A } \\
\text { bolsa tem vigência temporária de apenas } 3 \text { meses. }\end{array}$ \\
\hline $\begin{array}{l}\text { Apoio ao } \\
\text { Discente (PAD) }\end{array}$ & $\begin{array}{l}\text { O Programa objetiva ações afirmativas de permanência para os (as) alunos (as) com } \\
\text { fragilidade socioeconômica. Baseia-se em três modalidades: Bolsa de Apoio } \\
\text { Acadêmico e Auxílios Transporte e Alimentação e define normas que disciplinam o } \\
\text { desempenho acadêmico dos (as) discentes beneficiários (as). } \\
\text { - O apoio acadêmico constitui um direito do (a) discente, não é obrigatório o } \\
\text { desenvolvimento de atividade de pesquisa, extensão ou ensino. } \\
\text { - O auxílio transporte possibilita a mobilidade estudantil até a Instituição de ensino } \\
\text { superior. } \\
\text { - O auxílio alimentação objetiva assegurar auxílio financeiro para contribuir com } \\
\text { despesas mensais referentes a alimentação, substituindo o Restaurante Universitário } \\
\text { inexistente em algumas Unidades Acadêmicas. }\end{array}$ \\
\hline $\begin{array}{l}\text { Residência } \\
\text { Estudantil }\end{array}$ & $\begin{array}{l}\text { Prioriza discentes em situação de vulnerabilidade socioeconômica, que são } \\
\text { residentes de outros Estados e fora da região metropolitana do Recife. Os (as) } \\
\text { discentes contemplados (as) nesse Programa, também recebem Auxílio Manutenção } \\
\text { e gratuidade no restaurante universitário, quando não há disponibilidade de vagas, o } \\
\text { Auxílio Moradia pode ser implementado. }\end{array}$ \\
\hline Auxílio Moradia & $\begin{array}{l}\text { Objetiva assegurar auxílio financeiro para contribuir com despesas mensais } \\
\text { referentes à moradia do (a) estudante oriundo (a) de outros municípios e/ou que } \\
\text { sejam naturais do município onde se localiza o Campus, mas não possuem vínculos } \\
\text { familiares; oferecendo acompanhamento em todo o processo. }\end{array}$ \\
\hline Volta ao Lar & $\begin{array}{l}\text { Tem por finalidade custear, uma vez em cada semestre, ajuda de custo para os } \\
\text { discentes residentes visitarem seus familiares durante o recesso acadêmico. }\end{array}$ \\
\hline $\begin{array}{l}\text { Apoio à Gestante } \\
\text { (PAG) }\end{array}$ & $\begin{array}{l}\text { Tem como objetivo promover a permanência na Universidade das discentes que } \\
\text { tenham } 01 \text { (um) filho (a) após ingressarem em curso de graduação presencial e } \\
\text { apresentarem perfil de vulnerabilidade socioeconômica. A bolsa de Apoio } \\
\text { Acadêmico é concedida até que o (a) filho (a) complete } 3 \text { anos e } 11 \text { meses. }\end{array}$ \\
\hline $\begin{array}{l}\text { Incentivo à } \\
\text { Cultura (PIC) }\end{array}$ & $\begin{array}{l}\text { Tem como objetivo promover a inclusão cultural dos (as) discentes, } \\
\text { prioritariamente em vulnerabilidade socioeconômica e que apresentem aptidão } \\
\text { musical, durante a realização do curso de graduação presencial. }\end{array}$ \\
\hline $\begin{array}{l}\text { Bolsa de } \\
\text { Informática }\end{array}$ & $\begin{array}{l}\text { Tem por finalidade apoiar os discentes dos cursos de informática, visando à sua } \\
\text { formação complementar nos laboratórios de informática da Universidade, através } \\
\text { da disponibilidade de Bolsa de Informática. }\end{array}$ \\
\hline $\begin{array}{l}\text { Apoio a Jogos } \\
\text { Estudantis }\end{array}$ & $\begin{array}{l}\text { Tem por finalidade apoiar os (as) discentes esportistas, fornecendo ajuda de custo } \\
\text { para participarem de eventos esportivos. }\end{array}$ \\
\hline Hospeda Rural & $\begin{array}{l}\text { Visa à liberação de Auxílio Recepção/Hospedagem para discentes de graduação da } \\
\text { Universidade quando recebem estudantes estrangeiros (as) em sua residência, } \\
\text { através da Cooperação Internacional. }\end{array}$ \\
\hline Tutoria Discente & $\begin{array}{l}\text { Os (as) discentes em dificuldade de aprendizado são assistidos pela figura do tutor } \\
\text { discente. Este tutor acompanha as aulas a atua colaborando com o docente na } \\
\text { solução de temas da disciplina. Constitui um programa em fase de teste que está } \\
\text { funcionando em uma única unidade acadêmica (Unidade Acadêmica de Serra } \\
\text { Talhada). Seu objetivo principal é na minimização da retenção e evasão. }\end{array}$ \\
\hline $\begin{array}{l}\text { Restaurante } \\
\text { Universitário }\end{array}$ & $\begin{array}{l}\text { Apenas a SEDE dispõe de Restaurante Universitário (R.U). As refeições no R.U } \\
\text { são supervisionadas por nutricionista e economista doméstica, garantindo segurança } \\
\text { alimentar e o suprimento das necessidades nutricionais mínimas necessárias. }\end{array}$ \\
\hline $\begin{array}{l}\text { Atendimento } \\
\text { Psicossocial e }\end{array}$ & $\begin{array}{l}\text { O apoio Psicológico, Assistência Social e Pedagógico é comp } \\
\text { PROGESTI para atender seus discentes em todas as Unidades. }\end{array}$ \\
\hline
\end{tabular}




\begin{tabular}{|l|l|}
\hline Pedagógica & \\
\hline $\begin{array}{l}\text { Ajuda de Custo } \\
\text { para eventos } \\
\text { científicos }\end{array}$ & $\begin{array}{l}\text { Objetiva incentivar a participação de discentes em eventos científicos e/ou } \\
\text { acadêmicos estaduais, regionais e nacionais }\end{array}$ \\
\hline
\end{tabular}

Fonte: Dados da pesquisa - elaboração própria (2015)

Como especificado anteriormente, a Unidade Acadêmica analisada trata-se de uma Unidade recém-criada e sem residência estudantil. Realizou o seu primeiro processo seletivo para a modalidade de Auxílio Moradia no ano de 2015, oferecendo 20 vagas aos discentes em situação de vulnerabilidade socioeconômica e residentes fora da região urbana do Cabo de Santo Agostinho. Então, esse estudo, apesar de reconhecer as diversas modalidades de programas de assistência existentes na Universidade, apresentados anteriormente, foca sua análise na Modalidade acima prescrita uma vez que ela é a única a estar efetivamente implementada na referida unidade desde 2015.

\section{Percepção dos beneficiários do Programa de Auxílio Moradia}

A seguir são apresentados no gráfico 1, os dados sobre as percepções dos alunos beneficiários. Buscou-se identificar pontos de maior satisfação e insatisfação e assim contribuir com a gestão na melhoria do referido Programa.

Gráfico 1: A igualdade de oportunidades nas atividades acadêmicas

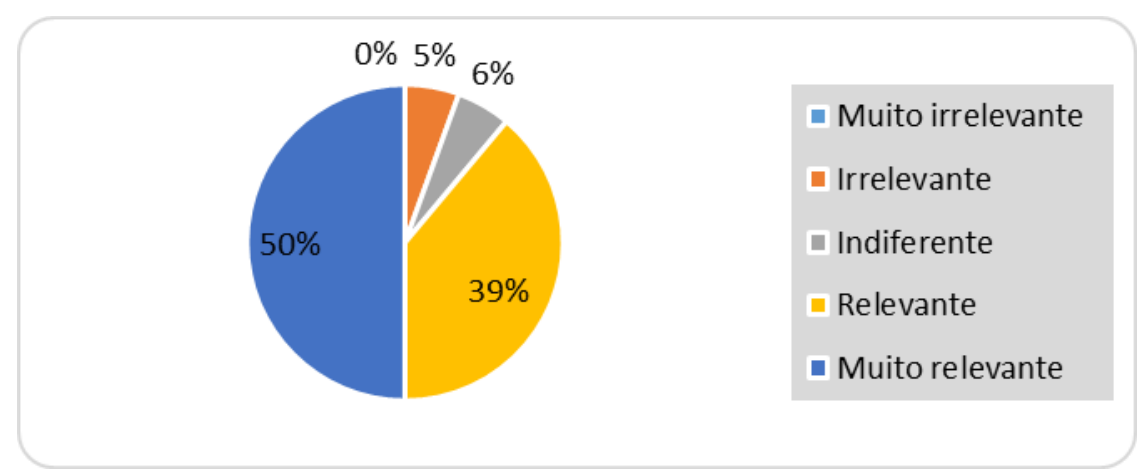

Fonte: Dados da pesquisa - elaboração própria

Quando demandados sobre a percepção de relevância do Auxílio Moradia sobre a igualdade de oportunidades nas atividades acadêmicas, observa-se que metade dos (as) entrevistados (as) declararam que o valor recebido é muito relevante. Quase 40\% destacaram como relevantes. Esse dado está em sintonia com o PNAES que estabelece que as ações de assistência estudantil devem considerar a necessidade de viabilizar a igualdade de oportunidades, contribuir para a melhoria do desempenho acadêmico e agir, 
preventivamente, nas situações de retenção e evasão decorrentes da insuficiência de condições financeiras.

Gráfico 2: A Redução dos efeitos das desigualdades socioeconômicas

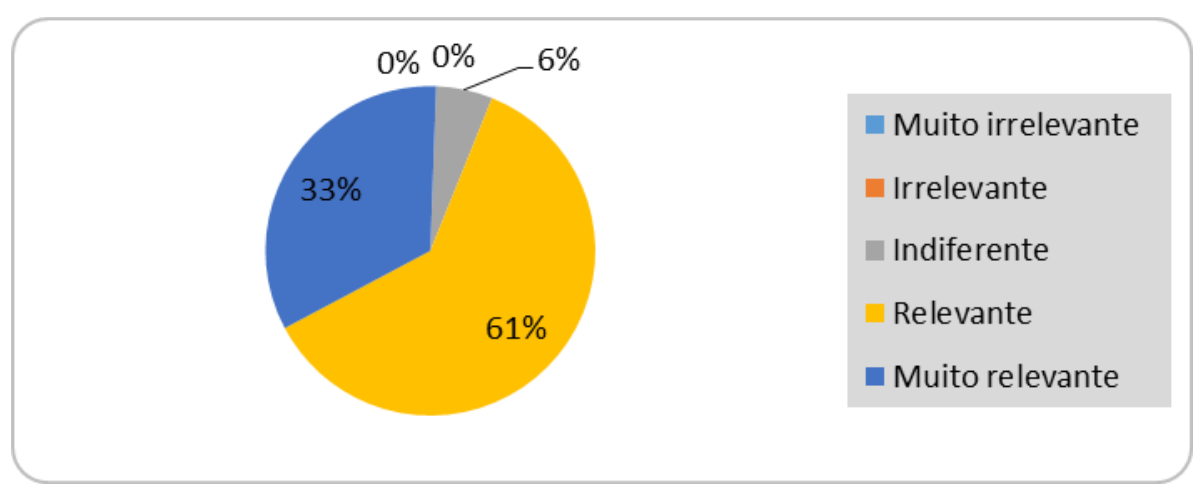

Fonte: Dados da pesquisa - elaboração própria

Sobre a percepção da redução dos efeitos das desigualdades socioeconômicas, durante o processo de análise, observa-se que cerca de 94\% dos (as) entrevistados (as) se posicionaram como relevante ou muito relevante. Isso demonstra, em consonância com o PNAES. O Programa de Auxílio Moradia, enquanto mecanismo de direito social, dá apoio aos estudantes, sobretudo os que vivenciam fragilidade socioeconômica, atendendo-os em suas necessidades básicas para que possam desenvolver suas atividades acadêmicas de forma eficaz.

Já quando perguntados sobre a percepção da permanência de estudos dos discentes em situação de vulnerabilidade socioeconômica, observa-se que 95\% dos (as) discentes reconhecem o Auxílio Moradia um Programa significativo (muito relevante ou relevante) para a sua permanência no curso de graduação.

Diante do explicitado, há de se observar que para diversos discentes, especialmente aqueles que vivenciam situação de fragilidade socioeconômica a única alternativa para a sua permanência no curso de graduação é a residência estudantil, visto a distância de sua casa de origem para a Universidade. Nesse sentido, verifica-se que a disponibilidade do auxílio moradia na Unidade em substituição as residências universitárias tem-se constituído como uma das principais estratégias de permanência pela Instituição, uma vez ser fundamental que os (as) discentes que não dispõe de recursos financeiros, tenham acesso a um local adequado para residir durante a sua graduação, garantindo, portanto, a 
continuidade do curso, como também a possibilidade do (a) estudante de viver o ambiente acadêmico com mais intensidade.

O resultado acima, se relaciona com a pergunta seguinte ao investigar a percepção dos resultados do Auxílio Moradia em relação a aspectos importantes do PNAES como redução da evasão escolar, promoção da inclusão social pela educação e aumento da permanência do (a) discente na instituição. Observa-se que, para 89\% dos (as) alunos (as), o referido programa é muito relevante ou relevante para a redução da taxa de evasão escolar. Apenas $11 \%$ declararam ser irrelevante para a questão analisada.

Diante do que foi colocado, julga-se importante destacar que apesar da implementação de ações e estratégias de Políticas de Assistência Estudantil para minimizar as desistências dos cursos, verifica-se que a temática é bastante complexa, pois conforme destacado por Platt Neto et al (2008), diversos motivos para o aumento do índice de evasão, que inclusive estão fora do controle institucional, entre esses estão: a falta de vocação ou perfil do(a) estudante para o curso; condições de doença; morte; a necessidade obter renda, etc.

Destarte, compreende-se que a situação de evasão não se limita apenas as condições de situação de vulnerabilidade socioeconômica, pois também existem outras motivações que permeiam a vida do (a) discente que ultrapassam o limite de atendimento da Assistência Estudantil.

No que diz respeito a percepção dos (as) discentes sobre a promoção da inclusão social pela educação, identificou-se que é o mesmo quantitativo da percepção sobre evasão (89\%). A partir da análise dessa categoria, observa-se a importância da efetivação de um Programa de Assistência Estudantil na Universidade, uma vez ser essencial para agregar cidadania, visto que a política social, em especial a de assistência estudantil, revertem-se em políticas afirmativas, de inclusão social, o que permite aos discentes além de ter acesso de forma igualitária ao ensino superior, também lhes propiciam novas oportunidades de ascensão social.

Diante do questionamento sobre a importância do auxílio para a manutenção do (a) discente, verifica-se que 100\% (cem) reconhece a sua dependência ao Programa de Auxílio Moradia para a continuidade no curso de graduação. Embora, reconheçam no Programa a possibilidade de sua permanência na Universidade, outras necessidades são apontadas como importantes, como destacado no resultado do Gráfico 3, a seguir, sobre a destinação do auxílio recebido. 
Gráfico 3: Destinação do Auxílio recebido

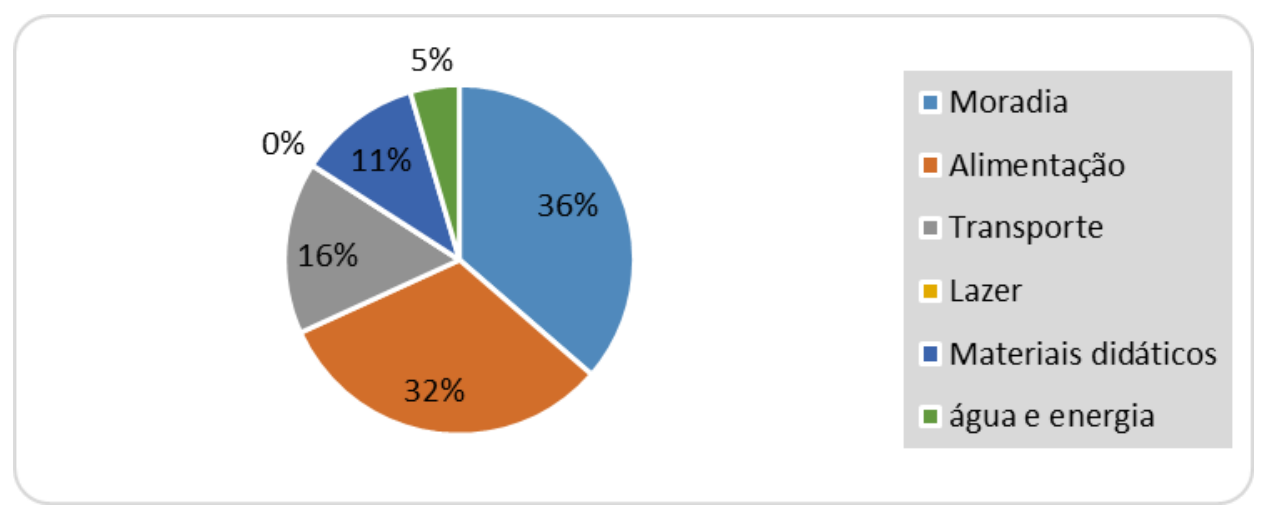

Fonte: Dados da pesquisa - elaboração própria

Leva-se também em consideração que os cursos da Unidade são em horário integral, dificultando o acesso dos (as) discentes ao mercado de trabalho formal, pela necessidade de dedicação integral ao curso, se faz relevante a assistência financeira da Instituição. A partir do gráfico apresentado acima, infere-se que apesar do benefício ter o objetivo de subsidiar as despesas de moradia ou apartamento, visto a ausência de Residência Estudantil na Unidade Acadêmica, nota-se que o auxílio tem sido utilizado para os diferentes gastos dos itens básicos relacionados como alimentação, transporte e materiais didáticos. Ressalta-se as respostas dadas aos gastos com alimentação, compreende-se, portanto, que a ausência de um Restaurante Universitário na Unidade também tem comprometido significativamente o auxílio que é direcionado para o custeio com moradia.

\section{Satisfação dos beneficiários do Programa de Auxílio Moradia}

Essa segunda parte foi direcionada à investigação da satisfação dos beneficiários com o Programa a partir da análise de alguns fatores como: valor do auxílio, processo de admissão realizado, disponibilidade de bolsas, pagamento e disseminação de informações.

Foi observado um grau de satisfação no valor do auxílio percebido pelos (as) beneficiários (as) de 73\%. Apesar de ser um número elevado de discentes considerando o valor como satisfeito ou muito satisfeito, vale destacar um número significativo dos (as) estudantes insatisfeitos quanto ao valor, cerca de $22 \%$. Salienta-se que no ano de 2015 as 
bolsas e auxílios da PROGESTI sofreram reajustes de até 10\%, aprovado em Resolução N ${ }^{\circ}$ 001/2015 do Conselho de Curadores.

O Auxílio Moradia até o ano de 2015 era de R\$ 310,00 (trezentos e dez reais), com reajuste de 7\% foi para $\mathrm{R} \$ 335,00$ (trezentos e trinta e cinco reais). Contudo, a partir da análise dos dados, verifica-se que alguns discentes consideram o auxílio insuficiente para o custeio de suas despesas e manutenção no curso de graduação.

Diante do que foi colocado, parte-se da perspectiva de que o grau de insatisfação do auxílio disponibilizado pela Universidade pode ser reflexo da crise econômica enfrentada pelo Brasil, em que a inflação impacta no poder de compra da população. Perante essa problemática, verifica-se o aumento de custo das famílias provocados pelas contas de energia, água, aluguel, etc.

Sobre o processo de admissão no programa, $78 \%$ dos (as) entrevistadas (as) consideram que a forma de divulgação do processo de admissão ao programa é satisfatória. Já 22\% indicam indiferença quanto a este quesito.

Ressalta-se que o processo de admissão consiste na avaliação das informações e documentações apresentadas ao Serviço Social, a partir da análise documental é verificado se o (a) discente se enquadra no perfil de família em situação de vulnerabilidade socioeconômica. Segundo o PNAES, é considerado vulnerável socioeconomicamente o (a) discente que comprovar renda familiar per capita igual ou inferior a 1,5 (um e meio) salário mínimo.

Após o processo de análise documental, é realizado entrevista social e, por fím, visita domiciliar, a fim da Instituição se aproximar da realidade socioeconômica da família do (a) discente. Portanto, aquele estudante que apresentar uma maior fragilidade socioeconômica será classificado no Programa e os demais ficarão na relação de classificáveis, aguardando a disponibilidade de vagas pela Pró-Reitoria. Caso seja identificado que o (a) aluno não apresenta o perfil apontado pela Resolução do Programa, o seu processo é indeferido, podendo, no entanto, recorrer do resultado.

Contudo, compreende-se que apesar dos princípios da Política de Assistência Estudantil, dispor como sendo um direito de todos os (as) discentes que vivenciam fragilidade socioeconômica, a limitação dos recursos financeiros impõe e afirmam cotidianamente a realização de processos seletivos, que não conseguem atender toda a demanda apresentada na IFES, tornando-se, portanto, um caráter excludente. 
Quando questionados sobre os critérios utilizados para a admissão no processo de seleção, verifica-se, dentre os (as) entrevistados (as), aqueles satisfeitos e muito satisfeitos que totalizam $89 \%$, entretanto, também, os $5 \%$ que declaram o seu grau de insatisfação.

Para o Programa de Auxílio Moradia, vale mencionar os requisitos para a sua candidatura. O (A) estudante deve atender, simultaneamente, os seguintes critérios: apresentar situação de vulnerabilidade socioeconômica; não pode residir na Região Urbana do município no qual a unidade se encontra; estar regularmente matriculado (a) em Curso de Graduação presencial e ter condições para concluir o curso dentro do prazo definido pela Universidade; não estar matriculado (a) em outra Instituição de Ensino Superior; não haver sido diplomado (a) em qualquer Curso de Graduação.

Ainda sobre o processo de admissão ao Programa, ressalta-se que $72 \%$ dos (as) acadêmicos (as) demonstram satisfação e 11\% enfatizam esse grau de satisfação referente ao prazo de submissão dos programas. Nesse sentido, pontua-se que para o Programa de Auxílio Moradia a Pró-Reitoria tem disponibilizado um prazo elástico desde o lançamento do edital até a publicação do resultado final. Diante do último edital divulgado no ano de 2016, observou-se que o lançamento do edital foi no início de fevereiro, já o período de inscrições iniciou no final de abril até a quinzena de maio. Com data para o resultado definitivo no fim de junho.

No que diz respeito a relação de documentos solicitados para a submissão do Programa, verifica-se, que apesar de alguns entrevistados demonstrarem indiferença, destacam-se os $78 \%$ e $17 \%$ dos (as) entrevistados (as) enfatizam a sua satisfação. Salientase, nesse caso, a fundamental importância no cumprimento do (a) discente na documentação exigida, uma vez que os documentos entregues subsidiam a análise do profissional de Serviço Social, pois traz elementos essenciais da situação socioeconômica familiar

O gráfico 4, a seguir, trata da satisfação em relação ao número de vagas disponibilizadas no Programa. Constatou-se que 56\% dos (as) bolsistas concordam que o número de vagas disponibilizadas pela Pró-Reitoria é insuficiente para atender a demanda de discentes com o perfil para o Programa de Auxílio Moradia, uma vez que se declararam como insatisfeito ou muito insatisfeito. 
Gráfico 4: O número de vagas disponíveis para o programa

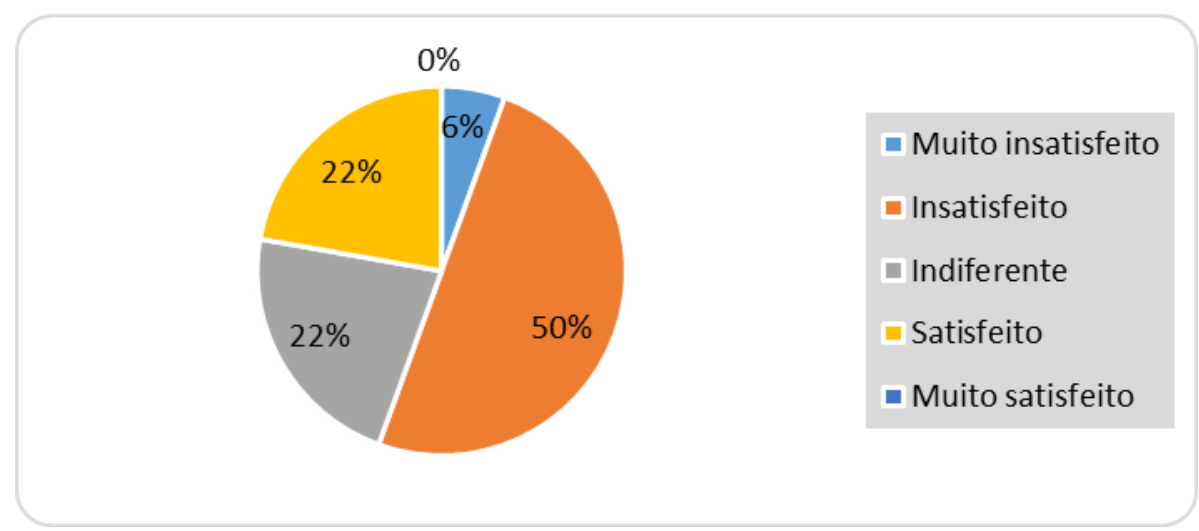

Fonte: Dados da pesquisa - elaboração própria

Vale mencionar que o quantitativo de vagas para o Programas de Assistência Estudantil é definido pela PROGESTI a partir da demanda reprimida. Como o Processo de Seleção de Auxílio Moradia de 2015 foi o primeiro, ainda não tinha sido realizado uma avaliação da situação de vulnerabilidade dos (as) acadêmicos (as). Nesse sentido, a PROGESTI disponibilizou no ano de 2015, o número de 20 vagas. Atualmente desse quantitativo, permanecem 18 estudantes assistidos (as) pelo Programa. Diante da primeira seleção e, a partir da análise da demanda reprimida, foi possível estabelecer as vagas para a seleção de 2016. Levando-se também em consideração a entrada de novos (as) graduandos (as).

Sobre o prazo de pagamento do auxílio moradia, percebe-se que existe uma satisfação acentuada com o prazo realizado. Ressalta-se que o pagamento das bolsas e auxílios são realizados até o $5^{\circ}$ dia útil de cada mês.

No que se refere a gestão das informações do Programa, não existe na Unidade Acadêmica uma equipe de profissionais que atenda as demandas dos (as) discentes sobre as questões administrativas. Para tanto, faz-se necessário um profissional da área administrativa para realizar levantamentos estatísticos, fazer a planilha de pagamento, bem como resolver as problemáticas referente a pagamento junto ao setor financeiro, etc. Pois, entende-se que a informação é elemento necessário para a efetivação das políticas públicas. 
Foi identificado, contudo, através da pesquisa realizada que os (as) discentes têm apresentado um grau de satisfação sobre o Apoio e esclarecimentos de dúvidas, que a PROGESTI juntamente com a profissional de Serviço Social tem dado na Unidade. Diante da análise das informações, verifica-se que 56\% apresentam-se satisfeitos e 33\% muito satisfeitos, enquanto $11 \%$ são indiferentes.

Contudo, diante da expansão da Unidade, com o aumento de turmas, compreendese, consequentemente um aumento da demanda para os Programas de recorte social, fazendo, portanto, ser de fundamental importância a implantação de uma equipe multiprofissional, composta por técnico administrativos, Técnicos em Assuntos Educacionais, Assistente Social, Psicólogo e Pedagogo, que atenda de forma integral essas demandas apresentadas.

A atuação da equipe profissional está diretamente relacionada com a divulgação e seleção dos Programas com os (as) usuários (as); fazer acompanhamento do rendimento acadêmico do (a) discente; dar apoio, sobretudo aos discentes em situação vulnerabilidade socioeconômica orientando-o quanto aos meios de resolver as dificuldades encontradas na vida Estudantil, proporcionado, portanto, melhores condições de vida universitária. A ampliação do número de profissionais, é, portanto, uma medida necessária para ampliar e qualificar os programas de assistência estudantil desenvolvidos na Unidade.

\section{Considerações finais}

O estudo realizado ressaltou que através da Promulgação da Constituição Federal de 1988 e, a aprovação de outras leis voltadas a educação, houve um avanço no sentido de compreender a educação como um direito social. Com o processo de expansão do ensino superior, a implementação da Política de Assistência Estudantil representou um avanço no que se refere a democratização do ensino superior, visto que, a assistência estudantil está voltada não apenas as ações de acesso à universidade pública, mas também aos mecanismos para a permanência e conclusão do curso de graduação, no sentido de minimizar os efeitos das desigualdades sociais e econômicos dos estudantes que apresentam dificuldades de darem continuidade a vida acadêmica.

A partir da coleta dos dados, verificou-se que os programas de auxílio moradia, contribui para minimizar as desigualdades de socioeconômicas a partir da realidade do público pesquisado, tendo em vista que permitem os (as) discentes a permanência no curso 
de graduação. O Programa, agrega, ainda, iniciativas voltadas para a democratização do acesso e a formação para a cidadania.

Em relação a destinação do auxílio, os dados demonstraram que o apoio financeiro destinado aos estudantes ultrapassa o objetivo fim, que é o suporte as despesas de moradia, interferindo, portanto, em outras despesas básicas de manutenção, tais como a alimentação, transporte, água, energia, dentre outros. Evitando, assim, a evasão do curso.

Considera-se também a fundamental importância da ampliação do Programa de Auxílio Moradia pela Pró-Reitoria, pois como especificado anteriormente, para diversos discentes a única alternativa para a sua permanência no curso de graduação é a residência estudantil. Nesse sentido, a disponibilidade do auxílio moradia em substituição as Residências Universitárias têm-se constituído como uma das principais estratégias de permanência.

Diante da análise realizada verifica-se que os (as) discentes pesquisados (as) reconhecem a importância da execução do Programa de Auxílio Moradia, bem como as ações e estratégias utilizadas para o seu desenvolvimento, contudo sugerem avanços necessários para o pleno atendimento.

Dentre esses avanços citados, destacam-se: o aumento no valor do benefício; avaliação contínua do desempenho acadêmico dos (as) beneficiados(as) a fim de incentiválos a continuarem no curso de graduação; a ampliação na quantidade de vagas disponibilizadas pela PROGESTI; ampliação do Programa de Auxílio Moradia, para também a inserção de auxílios transporte e alimentação e aumento do prazo de submissão da documentação para a seleção.

Portanto, considera-se que os programas de assistência estudantil se fazem necessário no sentido de viabilizar a igualdade de oportunidades de acesso e permanência de estudantes em situação de fragilidade socioeconômica, ou seja, garantir os direitos sociais.

Diante do conjunto de dados analisados, verifica-se que a PROGESTI tem desenvolvido ações em concordância com os objetivos estabelecidos pelo PNAES, bem como no atendimento aos discentes, entretanto, faz-se necessário que o investimento também seja para a melhoria dos recursos humanos, visto que a ampliação do número de profissionais que desenvolvam ações voltadas para a assistência estudantil traz um olhar mais crítico sobre as estratégias e programas em desenvolvimento. 
Nesse sentido, espera-se, que o trabalho tenha fornecido subsídios para a ampliação das discussões sobre as ações e estratégias da Política de assistência estudantil na Unidade Acadêmica. Pois, a pesquisa realizada, tem como um dos principais objetivos norteadores provocar mais debates sobre a temática, uma vez que busca contribuir para a tomada de decisões, e propiciar aos executores dos Programas de recorte social aperfeiçoar as práticas até então utilizadas.

\section{Referências}

ALVES, Jolinda Moraes. A assistência estudantil no âmbito da política de Ensino Superior Pública. Serviço Social em Revista, v. 5, n.1, jul/dez. 2002. Londrina-PR: UEL, 2002.

ARANHA, Maria Lúcia de Arruda. História da educação e da pedagogia. 3. ed. São Paulo: Moderna, 2006.

BAGGI, Cristiane Aparecida dos Santos. Evasão e avaliação institucional: uma discussão bibliográfica. Dissertação de Mestrado em Educação -Pontifícia Universidade Católica de Campinas. $\quad 2010 . \quad$ Campinas. Disponível em: <http://livros01.livrosgratis.com.br/cp155625.pdf>. Acesso em: 30 jun. 2016.

BELLONI, Isaura; MAGALHÃES, Heitor; SOUSA, Luzia Costa de. Metodologia para avaliação de políticas públicas: uma experiência em educação profissional. $4^{a}$ ed. São Paulo: Cortez, 2007. Coleção Questões da Nossa Época, v. 75.

BONETI, L. W. Políticas públicas por dentro. Ijuí (RS): Unijuí, 2007.

BRASIL. Decreto $\mathbf{n}^{\mathbf{0}}$ 6096, de 24 de abril de 2007. Programa de Apoio a Planos de Reestruturação e Expansão das Universidades Federais - REUNI, 2007. Disponível em: <http://www.planalto.gov.br/ccivil_03/_Ato2007-2010/2007/Decreto/D6096.htm>.

Acessado em: 27 maio 2016.

BRASIL. Decreto $\mathbf{n}^{\mathbf{0}} \mathbf{7 2 3 4}$, de 19 de julho de 2010. Programa Nacional de Assistência Estudantil - $\quad$ PNAES, 2010. Disponível em: <http://www.planalto.gov.br/ccivil_03/_Ato2007-2010/2010/Decreto/D7234.htm>. Acesso em: 26 maio 2016.

BRASIL. Lei $\mathbf{n}^{\circ}$ 12.711, de 29 de agosto de 2012. Lei de Cotas para o Ensino Superior, 2012. Disponível em: <http://www.planalto.gov.br/ccivil_03/_ato20112014/2012/lei/l12711.htm>. Acesso em: 28 maio 2016.

BRASIL. Ministério da Educação. A democratização e expansão da educação superior no país 2003 - 2014. Disponível em: <portal.mec.gov.br/docman/dezembro-2014/16762balanco-social-sesu-2003-2014>. Acess em: 28 maio 2016.

BRASIL. Ministério da Educação. Sistema Eletrônico do Serviço de Informação ao 
Cidadão Ministério da Educação, 2016. Disponível em: <http://esic.cgu.gov.br>. Acesso em: 28 maio 2016.

DANTAS, A. O.; ARAUJO, J. O. A Questão do Financiamento da Assistência Estudantil nos Trâmites da Reforma Universitária do Governo Lula. In: ARAUJO, J. O.; CORREIA, M. V. C. (org.). Reforma Universitária. Maceió: EDUFAL, 2005.

GUARESCHI, N. Problematizando as práticas psicológicas no modo de entender a violência. In: STREY, Marlene (Org.). Violência, gênero e políticas públicas. Porto Alegre: EDIPUCRS, 2004.

\section{GEORGEN, Pedro. Educação Superior na perspectiva do sistema e do Plano Nacional} de Educação. Campinas, SP., 2010. Disponível em: <www.scielo.br/pdf/es/v31n112/13.pdf>. Acesso em: 31 maio 2016.

MARCONI, Marina de Andrade; LAKATOS, Eva Maria. Metodologia do trabalho científico. $7^{\text {a }}$ edição, São Paulo, atlas 2009.

MUGNOL, Márcio; GISI, Maria de Lourdes. Avaliação de Políticas Públicas Educacionais: Os Resultados do PROUNI. IX ANPED Sul. Seminário de Pesquisa em $\begin{array}{llllll}\text { Educação da } & \text { Região } & \text { Sul } & \text { Disponível }\end{array}$ <www.ucs.br/etc/conferencias/index.php/anpedsul/9anpedsul/paper/view/2022/970>.

Acesso em: 02 jun. 2016.

OLIVEIRA, Romualdo Portela de. (1989), A educação na Nova Constituição: mudar para permanecer. Revista da Faculdade de Educação, 15(1):16-27, jan.-jun. São Paulo, FEUSP. Disponível em: <http://www.revistas.usp.br/rfe/article/view/33426/36164>. Acesso em: 12 jun. 2016.

PEREIRA, P. A. P. Discussões conceituais sobre política social como política pública e de direito de cidadania. In: BOSCHETTI, I. (Org.). Política social no capitalismo: tendências contemporâneas. São Paulo: Cortez, 2009.

PLATT NETO, O. A. da; CRUZ, F.; PFITSCHER, E. D. Utilização de metas de desempenho ligadas à taxa de evasão escolar nas universidades públicas. Revista de Educação e pesquisa em Contabilidade. Brasília, v.2, art.4, maio/agosto 2008. Disponível em: <http://www.repec.org.br/index.php/repec/article/view/25/27>. Acesso em: 13 jul. 2016.

SILVA, E. G. Desempenho Institucional: a política de qualificação dos docentes da UESB. 2009. 134 f. Dissertação (Mestrado) - UNEB / Departamento de Ciências Humanas, Salvador.

VAITSMAN, J.; RODRIGUES, R.W.S.; SOUSA, R.P. O Sistema de Avaliação e Monitoramento das Políticas e Programas Sociais: a experiência do Ministério do Desenvolvimento Social e Combate à Fome do Brasil. Brasília: Unesco, 2006. Disponível em: <unesdoc.unesco.org/images/0014/001485/148514por.pdf>. Acesso em: 02 jun. 2016. 
VASCONCELOS, Natalia Batista. Programa Nacional de Assistência Estudantil: uma análise da evolução da Assistência estudantil ao longo da história da Educação Superior no Brasil. Revista da Católica. Uberlândia, 2010. Disponível em: <http://www.catolicaonline.com.br/revistadacatolica2/artigosv2n3/29-Pos-Graduacao.pdf >. Acesso em: 27 maio 2016.

\section{Como referenciar este artigo}

BARBOSA, Alba. Programa de auxílio moradia em uma unidade acadêmica de uma universidade de Pernambuco: uma avaliação na perspectiva dos (as) discentes beneficiados. Revista on line de Política e Gestão Educacional, Araraquara, v.21, n.01, p. 125-145, 2017. Disponível em: 〈http://dx.doi.org/10.22633/rpge.v21.n.1.2017.9989>. ISSN: 1519-9029.

Submetido em: 10/11/2016

Aprovado em: 30/03/2017 